\title{
COMPARISON OF SEGMENTATION METHODS USED FOR BONE FRACTURE IMAGES
}

\author{
Salih BÜTÜNER1 [0000-0003-0737-4016], Eftâl ŞEHİRLİ [0000-0003-0511-1933] \\ ${ }^{1}$ Karabük University, Computer Engineering Department, Karabük, Turkey - salihbutuner@yandex.com \\ ${ }^{2}$ Karabük University, Medical Engineering Department, Karabük, Turkey - eftalsehirli@karabuk.edu.tr
}

KEYWORDS: Bone Fracture, Image Processing, Segmentation Methods, Thresholding, Fracture Diagnosis

\begin{abstract}
:
The usage of computers and software in the biomedical field has been increasing and applications for doctors, clinicians, scientists and other users have been developed in the recent times. Manual, semi-automatic and fully automatic applications developed for bone fracture detection are one of the important studies in this field. Image segmentation, which is one of the image preprocessing steps in bone fracture detection, is an important step to obtain successful results with high accuracy. In this study, Otsu thresholding method, active contour method, k-means method, fuzzy c-mean method, Niblack thresholding method and max min thresholding range (MMTR) method are used on bone images obtained by Karabük University Training and Research Hospital. When any filters are not applied on images to remove noises, the most successful method is obtained by K-means method based on specificity and accuracy as $89,55 \%$ and $83,31 \%$ respectively. Niblack thresholding method has the highest sensitivity result as $92,45 \%$.
\end{abstract}

\section{INTRODUCTION}

Imaging processes and software applications, which are an effective way for diagnosis and treatment in the biomedical field, are becoming increasingly popular. These two fields provide great convenience to doctors, clinicians, scientists and medical device users. Software applications that can automatically analyze are helpful tools used to extract information about subjects like disease diagnosis, organ damage, experimental studies and fracture detection, etc.

One of the projects carried out in the biomedical field in recent years is to detect bone fractures in any part of the body and inform physicians and radiologists about them. While applications in biomedical field carry out these processes, the necessary images are obtained from biomedical imaging devices. The quality of images is very crucial for the high accuracy of features to be detected or information to be extracted.

Bones are one of the most important building blocks of the skeletal system, which keeps the human standing, gives shape to the body and can perform limited movements. Bone, which has an organic structure, is a living organism consisting of approximately $70 \%$ mineral, $22 \%$ protein and $8 \%$ water (Bayram and Çakıroğlu, 2016). Bones are mostly made up of a substance called matrix. Bones are very hard due to the large amount of calcium they contain. Based on this hardness, they can be cracked and broken by the direct or indirect force coming from the outside (Marolt et al., 2010) (Veysi, 2007).

Fracture means the separation or deterioration of bone integrity that occurs in the bone due to external or internal forces (Wang and Puram, 2004).

At the present time, bone fractures are monitored by biomedical imaging devices such as X-ray, MRI (Magnetic Resonance Imaging), Scintigraphy and CT (Computerized Tomography). In general, DICOM (Digital Imaging and Communication in Medicine) is used in medical imaging systems, which contains more information about patients than other image formats. Formats such as .jpg, .jpeg, .png, .tiff are also preferred in digital images (Öztürk and Kutucu, 2017). Digital image processing methods aim to present the desired and researched information for users by processing the digital images.

Studies in biomedical field in the literature have used computer hardware and software very effectively and frequently in recent years. One of the most preferred subjects among subjects that provide development and improvement in biomedical field is digital image processing and analysis applications. Eksi et al. has developed an application based on ANN (Artificial Neural Networks) that can detect fractures on long bones. In their study, arithmetic mean filter and three different thresholding methods such as k-means clustering, fuzzy c-mean and Otsu were carried out on x-ray images. Otsu thresholding method was preferred as the most accurate algorithm. (Eksi and Cakiroglu, 2012). Öztürk et al. detected bone fractures using Artificial Neural Networks in their study. They achieved $89 \%$ success by choosing the K-Mean algorithm as the segmentation algorithm (Öztürk and Kutucu, 2017). Bayram et al. detected and classified femoral bone fractures using Support Vector Machines (SVM). They used Niblack segmentation method in the image segmentation phase and achieved $89.87 \%$ success rate (Bayram and Çakıroğlu, 2016). Öztürk et al. compared the segmentation methods and emphasized that the preference may change according to the usage conditions (Öztürk and Öztürk, 2018).

The aim of this study is to compare the segmentation methods used in studies on bone fracture images, find the most successful one and why the preferred method should be applied on the bone fracture images. Segmentation methods, which are widely used in the literature for the detection of bone fractures, were applied on same sample images and compared with both each other and expert's result in this study.

\section{MATERIAL AND METHOD}

\subsection{Material}

20 images used in this study were obtained by Karabük Training and Research Hospital in jpg, jpeg, DICOM formats in color. Matlab is preferred to apply segmentation methods on bone fracture images. Expert also used Matlab to obtain the accurate binary images. Matlab provides an easy use with its user-friendly 
interface and built-in functions. Mathematical processing capability of Matlab is very fast. Besides, its matrix-based operation, it also has superior graphical ability. Matlab has builtin functions, algorithms and simulations specially prepared for many topics like digital image processing, digital signal processing, data analysis (Özkan, 2010).

\subsection{Method}

Digital image processing contains processes like filtering, image enhancement, segmentation, image recognition feature extraction used to obtain the desired details and objects on digital images in the computer environment. Image segmentation is a very important step in terms of the quality of the extracted feature and obtaining all the details such as the condyle of the desired region, the region of the fracture, and the angle on bone fracture images. Therefore, the success of the segmentation method directly affects the success of operations to be applied in the next stages (Öztürk and Kutucu, 2017). Segmentation contains processes to obtain the desired region(s) on digital images by utilizing image features (Öztürk and Öztürk, 2018). For bone fractures, the aim of the segmentation is to obtain bone tissue separated from other tissues or background. Since pixel values of bones and other tissues on X-ray images are close to each other, the quality of the segmentation process is very important. In this study, Otsu thresholding method, active contour method, K-means method, fuzzy c-mean method, Niblack thresholding method and MMTR are applied on bone fracture images.

2.2.1 Otsu Thresholding Method: The Otsu method is a thresholding method that works on gray level images and processes according to the range of different color values on the image. A thresholding value converts gray level image to binary image. The threshold value is determined by minimizing the variance of within-class intensity or by maximizing the variance between classes (Sezgin and Sankur, 2004)(Otsu, 1979). All calculations to find a thresholding value are based on histogram values. In Otsu method, the threshold value can be obtained by approximating the variance value determined by the weights of the pixels of the object and the background to the minimum. While the variance value within the class decreases, the variance value between the classes increases.

The formula for threshold value calculation is given in Eq. 1-3.

$$
\sigma^{2}=\sum_{i=0}^{N-1}\left(x_{i}-\mu_{x}\right) \operatorname{Pr}\left\{x_{i}\right\}
$$

Where $\operatorname{Pr}\left\{x_{i}\right\}=$ the probability of $x_{i}$

$$
\begin{aligned}
\sigma_{\text {black }}= & \sigma-\sigma_{\text {white }}=\omega_{1}(t) \omega_{2}(t)\left(\mu_{1}(t)-\mu_{2}(t)\right)^{2}, \\
\omega_{1}(t) & =\sum_{i=0}^{t} \operatorname{Pr}\{i\} \\
\omega_{2}(t) & =\sum_{i=t+1}^{255} \operatorname{Pr}\{i\} \\
\mu 1(t) & =\sum_{i=0}^{t} \operatorname{Pr}\{i\} H(i) \\
\mu 2(t) & =\sum_{i=t+1}^{255} \operatorname{Pr}\{i\} H(i)
\end{aligned}
$$

where

$$
\begin{aligned}
& \omega=\text { variance densities } \\
& \mu=\text { weighted class average }
\end{aligned}
$$

While variance is calculated by Eq. 2, variance within class and between classes are calculated by Eq 2 and 3, respectively (Kaygısız and Çakır, 2020). Since the calculation of the variance between classes is less computational, the threshold value is taken as the value at which the variance between classes is maximum or the variance within class is minimum (Kır Savas et al., 2017). In this study, bone fracture images are converted to binary images by Otsu thresholding method and the obtained results are presented in Fig $1 \mathrm{~b}$.

2.2.2 Active Contour Method (Snake): Active contour model also known as snake model is an energy-based method. Initial curves are determined on the image. Then, the boundaries of the desired object or region are separated from the background with the movement of the active contour curves towards the object boundaries. The determined curves are as many as the number of iterations. Active contour model allows semiautomatic segmentation by minimizing number of iteration and active contour energy function (Bresson et al., 2007). In this study, bone fracture images are converted to binary images by active contour method and the obtained results are presented in Fig 1c.

2.2.3 K-Means Method: K-means method introduced by MacQueen in 1967 is an unsupervised clustering method widely used in data mining and machine learning. It is used to cluster data sets with similar properties (Sun et al., 2008). The K-means method is also used for segmentation. This method is based on converging the objects in a given image to their local minimum point and obtaining $\mathrm{k}$ different clusters ( $\mathrm{Na}$ et al., 2010). This method composes of four stages.

i. Random center selection for each cluster by choosing the $\mathrm{k}$ value.

ii. Moving each object to the center closest to it.

iii. Calculate centroids for each cluster.

iv. Do second and third until centroid does not change. When centroids for each cluster stay stable, stop the method.

In order to move objects to the closest cluster, the Euclidean distance between object and cluster centers is usually calculated. When all objects are placed in $\mathrm{k}$ different clusters, early clustering is achieved and iterations continue until the criterion function approaches the minimum. Criterion function is calculated in Eq 4 shown as below (Na et al., 2010).

$$
E=\sum_{i=1}^{k} \sum_{x \in C_{i}}\left|x-x_{i}\right|^{2}
$$

where

$$
\begin{aligned}
& x=\text { object } \\
& x_{i}=\text { mean of } C_{i} \text { cluster } \\
& E=\text { criterion function }
\end{aligned}
$$

$E$ is the sum of the squares of the error obtained by all objects. The distance for the criterion function is obtained by the Euclidean distance as in equation (5).

$$
d=\sqrt{\sum_{i=1}^{n}\left(x_{i}-y_{i}\right)^{2}},
$$

where $\quad x_{i}=\mathrm{x}$ coordinate of ith point

$y_{i}=\mathrm{y}$ coordinate of ith point

$$
d=\text { distance for criterion function }
$$

In other words, Euclidean distance is the distance between each object and its closest cluster center. The clustering iteration process continues until there is no change in the centers of the clusters (Na et al., 2010). In this study, k value is selected as 2. While one cluster represents bone object, another cluster represents background. Bone fracture images are converted to binary images by K-means method and the obtained results are presented in Fig 1d. 
2.2.4 Fuzzy C-Means Method: Fuzzy c-means method is an algorithm introduced by Dunn in 1973 and developed by Bezdek in 1981. The difference between fuzzy c-means and k-means method is that one sample can locate at two or more clusters for fuzzy c-means method. Due to the fuzzy C-means logic, each sample can have a membership value between [0,1]. When a sample is closer to a cluster, the membership value for that cluster is high. The desired situation is that the sum of all membership values for a sample should be 1 (Meltem and Çamurcu, 2010)(Yavuz and Köse, 2013)(Naik et al., 2019). The formulas used for fuzzy c-means method are presented in Eq 6-7.

$$
\begin{aligned}
& V i=\frac{\sum_{k=1}^{n} u_{i k}{ }^{m} x_{k}}{\sum_{k=1}^{n} u_{i k}^{m}}, \\
& u_{i k}=\frac{\left[\frac{1}{\left(x_{k}-v_{i}\right)^{2}}\right]^{\frac{1}{m-1}}}{\sum_{j=1}^{c}\left[\frac{1}{\left(x_{k}-v_{i}\right)^{2}}\right]^{\frac{1}{m-1}}},
\end{aligned}
$$

where $\quad c=$ number of clusters

$n=$ number of samples

$m=$ a weight exponent

$U=$ membership matrix

$t=$ iteration count

$V=$ center of clusters

First of all, values of $\mathrm{c}, \mathrm{n}$ and $\mathrm{m}$ parameters are determined. $\mathrm{U}$ membership matrix has cxn in size. $U^{0}$ membership matrix can be assigned with random numbers or manual number selections. Declaration for iteration count is done. Centroid of clusters for $V^{t}$ is calculated. Then, next membership matrix is calculated and centroids for each cluster is updated. This process is repeated until this process is repeated until the algorithm becomes stable (until the error comes under the threshold value) (Yavuz and Köse, 2013). In this study, c is selected as 2 in order to separate image pixels as bone and background. The obtained results are presented in Fig 1e.

2.2.5 Ni-Black Thresholding Method: Niblack is a histogram-based thresholding method. In this method, a kernel is walked through image. A local thresholding value is determined by adding local means and local standard deviations in kernel. This is presented in Eq 8.

$$
T(i, j)=m_{z}(i, j)+k \sigma_{z}(i, j),
$$

where $\quad \mathrm{z}=$ kernel window

$\mathrm{T}=$ thresholding value

$\mathrm{k}=$ coefficient

$\mathrm{m}=$ mean of kernel $\mathrm{z}$

$\sigma_{z}=$ standard deviation of kernel z

In this study, $\mathrm{k}$ is selected as $-0,002$. The obtained results are presented in Fig 1f (Bayram and Çakıroğlu, 2016)(Niblack, 1985).
2.2.6 Max Min Thresholding Range (MMTR) Method: MMTR is a histogram-based thresholding method. A local thresholding value is calculated by referencing the max and min points of the image histogram. In this method, image in mxn size is converted to grayscale. A new image form is obtained by using Equation 9. Histogram of the obtained image is calculated. The histogram is normalized by using Equation 10. Class variance values of image is calculated based on histogram values and $[0,255]$ color intensity values. The maximum value is assigned as thresholding value as shown a code block (Malik et al., 2010)(Malik et al., 2011).

$$
I=255 \times(I-\min (I) /(\max (I)-\min (I))),
$$

where $\quad I=$ gray image

$$
n f=\frac{f}{m \times n},
$$

where $\quad n f=$ normalized frequency

$$
m \times n=\text { size of matrix }
$$

A code block of this method is shown below;

for $\mathrm{i}=1: 255-1$

$$
\begin{aligned}
& \mathrm{P}_{1}=\operatorname{sum}(\operatorname{nf}(1: \mathrm{i}+1)) \\
& \mathrm{P}_{2}=\operatorname{sum}\left(\left(\operatorname{nf}(1: \mathrm{i}+1) . *(0: i)^{\prime}\right)\right) \\
& \text { Classvariance }(\mathrm{i}+1)=\left(\operatorname{means}(\mathrm{I}) * \mathrm{P}_{1}-\mathrm{P}_{2}\right)^{\wedge} 2 /\left(\mathrm{P}_{1} *\left(1-\mathrm{P}_{1}\right)\right)
\end{aligned}
$$

end

$[\sim$, index $]=\max ($ Classvariance $)$;

Result $=\mathrm{I}>$ index;

In this study, this method is applied on bone fracture images and the obtained results are presented in Fig 1g.

2.2.7 Validation of Methods: In this study, expert results are compared with results obtained by each segmentation method on same images. Confusion matrix is created based on comparison results. Confusion matrix is used to summarize and validate results. It composes of four parameters as True Positive (TP), False Positive (FP), False Negative (FN) and True Negative (TN). TP stands for correctly identified bone pixels. FP stands for incorrectly identified bone pixels. FN stands for incorrectly rejected bone pixels. TN stands for correctly rejected bone pixels. Mathematical descriptions of sensitivity, specificity and accuracy are given in Equations 11-13 (Fawcett, 2006).

$$
\text { Sensitivity }=\frac{T P}{T P+F N},
$$

$$
\text { Specificity }=\frac{T N}{T N+F P}
$$

$$
\text { Accuracy }=\frac{T P+T N}{T P+T N+F P+F N},
$$




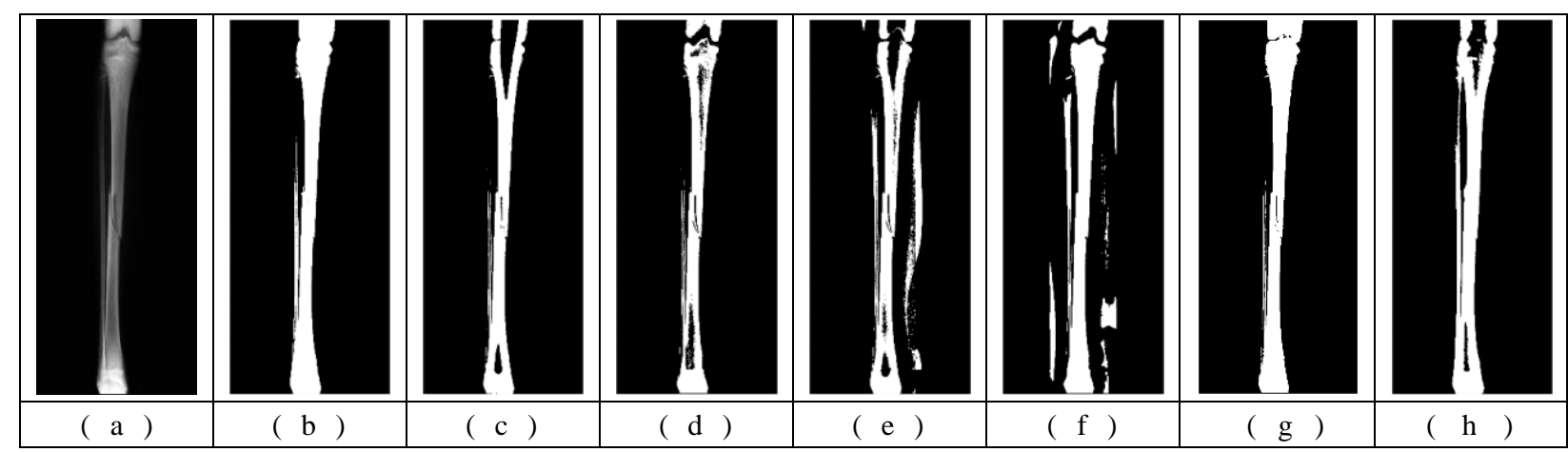

Figure 1. Comparison of segmentation methods. (a) A sample original image. (b) Image obtained after Otsu thresholding method. (c) Image obtained after active contour method, (d) Image obtained after K-means method. (e) Image obtained after fuzzy c-means method, (f) Image obtained after Niblack thresholding method. (g) Image obtained after MMTR. (h) Image obtained by the Expert.

\section{EXPERIMENTAL RESULTS AND CONCLUSION}

Image segmentation is one of the most important digital image processing steps to obtain desired objects on images. In this study, segmentation methods are applied and compared on bone fracture images shared by Karabük University Training and Research Hospital in order to separate bone objects and background. A total of 20 images were used to compare the segmentation algorithms and the obtained results for a sample image are visually presented in Fig 1. Average sensitivity, specificity and accuracy values of each segmentation method is presented in Table 1.

\begin{tabular}{|l|c|c|c|}
\hline \multicolumn{1}{|c|}{ Method } & $\begin{array}{c}\text { Sensitivity } \\
(\mathbf{\%})\end{array}$ & $\begin{array}{c}\text { Specificity } \\
(\mathbf{\%})\end{array}$ & $\begin{array}{c}\text { Accuracy } \\
(\boldsymbol{\%})\end{array}$ \\
\hline Otsu & 77,69 & 71,42 & 72,22 \\
\hline Active contour & 65,47 & 74,18 & 69,82 \\
\hline K-means & 76,17 & 89,55 & 83,31 \\
\hline Fuzzy c-means & 48,94 & 74,95 & 66,73 \\
\hline Niblack & 92,45 & 71,13 & 77,10 \\
\hline MMTR & 73,65 & 70,13 & 70,32 \\
\hline
\end{tabular}

Table 1. Sensitivity, specificity and accuracy values of methods.

As can be seen from Table 1, the most successful results are obtained by K-means method based on specificity and accuracy parameters. Niblack thresholding method has the greatest result based on sensitivity parameter. It has been observed that the active contour method and fuzzy c-means method are not better than other segmentation methods. It can be concluded that bone fracture and condyle influence the results negatively. It has been observed that pixels belonging to background and bone fracture region are very similar at many transition points.

\section{ACKNOWLEDGEMENTS}

Authors thanks Karabük University Training and Research Hospital to share bone images under ethical committee approval.

\section{REFERENCES}

Bayram, F., Çakıroğlu, M., 2016. ScienceDirect Diffract: Diaphyseal Femur Fracture Classifier SysTem. Biocybernetics and Biomedical Engineering. 36 (1), 157-171. https://doi.org/10.1016/j.bbe.2015.10.003.

Bresson, X., Esedoglu, S., Vandergheynst, P., Thiran, J.P., Osher, S., 2007. Fast Global Minimization of the Active Contour/Snake Model. Journal of Mathematical Imaging and
Vision. 28, 151-161. https://doi.org/10.1007/s10851-007-00020 .

Eksi, Z., Cakiroglu, M., 2012. Performance evaluation of the popular segmentation algorithms for bone fracture detection. AWERProcedia Information Technology \& Computer Science. $1,1245-1249$.

Fawcett, T., 2006. An introduction to ROC analysis. Pattern $\begin{array}{llll}\text { Recognition } & \text { Letters. } & 27 & \text { (8), }\end{array}$ https://doi.org/10.1016/j.patrec.2005.10.010

Kaygısız, H., Çakır, A., 2020. FPGA Kullanılarak Görüntülerin Gerçek Zamanlı Olarak OTSU Metodu ile Bölütlenmesi. European Journal of Science and Technology. 18, 911-917. https://doi.org/10.31590/ejosat.682278

Kır Savaş, B., İlkin, S., Hangişi, S., Şahin, S., 2017. Gölge Tespitinde Kullanılan Bayes Sinıflandırma, Otsu Bölütleme ve Histogram Dağılımı Yöntemlerinin Karşılaştırılması. Düzce Üniversitesi Bilim ve Teknoloji Dergisi. 5, 345-355.

Malik, J., Dahiya, R., Sainarayanan, G., 2011. Harris Operator Corner Detection using Sliding Window Method. International Journal of Computer Applications. 22, 28-37. https://doi.org/10.5120/2546-3489.

Malik, J., Sainarayanan, G., Dahiya, R., 2010. Min Max Threshold Range (MMTR) based approach in palmprint authentication by sobel code method. Procedia Computer $\begin{array}{lll}\text { Science. } & 2, & 149-158 .\end{array}$ https://doi.org/10.1016/j.procs.2010.11.019.

Marolt, D., Knezevic, M., Novakovic, G.V., 2010. Bone tissue engineering with human stem cells Bone tissue engineering with human stem cells. Stem cell research \& therapy. 10. https://doi.org/10.1186/scrt10.

Meltem, I., Çamurcu, A.Y., 2010. K-Means Ve Aşırı Küresel CMeans Algorıtmaları İle Belge Madenciliği. Marmara Fen Bilimleri Dergisi. 22, 1-18. https://doi.org/10.7240/mufbed.69983.

Na, S., Xumin, L., Yong, G., 2010. Research on k-means Clustering Algorithm: An Improved k-means Clustering Algorithm. Third International Symposium on Intelligent Information Technology and Security Informatics. 63-67. https://doi.org/10.1109/IITSI.2010.74.

Naik, N., Jenkins, P., Savage, N., Yang, L., 2019. Cyberthreat Hunting - Part 2: Tracking Ransomware Threat Actors using 
Fuzzy Hashing and Fuzzy C-Means Clustering. IEEE International Conference on Fuzzy Systems. 1-6. https://doi.org/10.1109/FUZZ-IEEE.2019.8858825.

Niblack, W., 1985: An introduction to Digital Image Processing, Prenrice-Hall.

Otsu, N., 1979, A threshold selection method from gray-level histograms. IEEE Transactions on Systems, Man, and $\begin{array}{llll}\text { Cybernetics. } & 9 & \text { (1), }\end{array}$ https://doi.org/10.1109/TSMC.1979.4310076.

Özkan, M.V., 2010. Matlab Görüntü İşleme Aracı Kullanarak Endometriozis Hastalığının Ultrason Görüntülerinde Tespiti. Frrat Üniversitesi.

Öztürk, N., Öztürk, S., 2018. Görüntü Bölütleme Yöntemlerinin Karşılaştırılması. 2018 International Conference on Artificial Intelligence and Data Processing (IDAP). 1-4 https://doi.org/10.1109/IDAP43944.2018

Öztürk, Ö., Kutucu, H., 2017. Detection of Bone Fractures using Image Processing Techniques and Artificial Neural Networks. 2017 International Artificial Intelligence and Data Processing Symposium (IDAP). $1-5$.
Sezgin, M., Sankur, B., 2004. Survey over image thresholding techniques and quantitative performance evaluation. Journal of Electronic Imaging https://doi.org/10.1117/1.1631316

Sun, J., Liu, J., Zhao, L., 2008. Clustering algorithms Research. Journal of Software. 19, 48-61. https://doi.org/10.3724/SP.J.1001.2008.00048

Türe, H., Başer, F., 2016. Country risk assessment with fuzzy cmeans clustering algorithm. Ekonometri ve İstatistik Dergisi. 1633.

Veysi, A., 2007. Kemik mineral yoğunluğunun yapay sinir ağlarıyla saptanması. Dicle Üniversitesi.

Wang, X., Puram, S., 2004. The toughness of cortical bone and its relationship with age. Annals of Biomedical Engineering. 32, $123-135$

https://doi.org/10.1023/B:ABME.0000007797.92559.5e

Yavuz, Z., Köse, C., 2013. Bulanık C - Kümeleme Algoritması ile Retinal Kan Damarı Bölütleme Retinal Vessel Segmentation with Fuzzy C-Means Clustering Algorithms. EMO Bilimsel Dergi. 3, 562-566. 